\title{
Article \\ Ampicillin Plus Ceftriaxone Combined Therapy for Enterococcus faecalis Infective Endocarditis in OPAT
}

\author{
Laura Herrera-Hidalgo ${ }^{1,2}$, Jose Manuel Lomas-Cabezas ${ }^{2}$, Luis Eduardo López-Cortés ${ }^{3}$ (D), Rafael Luque-Márquez ${ }^{2}$, \\ Luis Fernando López-Cortés ${ }^{2}$ (D), Francisco J. Martínez-Marcos ${ }^{4}$, Javier de la Torre-Lima ${ }^{5}$, \\ Antonio Plata-Ciézar ${ }^{6}{ }^{(D}$, Carmen Hidalgo-Tenorio ${ }^{7}$ (D), Maria Victoria García-López ${ }^{8}$, David Vinuesa ${ }^{9}$, \\ Alicia Gutiérrez-Valencia ${ }^{2}$, Maria Victoria Gil-Navarro ${ }^{1, *}$ and Arístides De Alarcón ${ }^{2}$ on behalf of the \\ Cardiovascular Infectious Study Group of the Andalusian Society of Infectious Diseases
}

1 Unidad de Farmacia, Hospital Universitario Virgen del Rocío/CSIC/Instituto de Biomedicina de Sevilla (IBiS), 41013 Seville, Spain; lauraherrerahidalgo@gmail.com

2 Unidad Clínica de Enfermedades Infecciosas, Microbiología y Medicina Preventiva, Hospital Universitario Virgen del Rocío/CSIC/Instituto de Biomedicina de Sevilla (IBiS), 41013 Seville, Spain; jlomascabezas@yahoo.es (J.M.L.-C.); rafael.luque.sspa@juntadeandalucia.es (R.L.-M.); luisfernando@lopezcortes.net (L.F.L.-C.); alicia.gutierrez.valencia@gmail.com (A.G.-V.); aa2406ge@yahoo.es (A.D.A.)

3 Unidad Clínica de Enfermedades Infecciosas, Microbiología y Medicina Preventiva, Hospital Universitario Virgen Macarena/CSIC/Instituto de Biomedicina de Sevilla (IBiS), 41009 Seville, Spain; luiselopezcortes@gmail.com

check for updates

Citation: Herrera-Hidalgo, L.; Lomas-Cabezas, J.M.; LópezCortés, L.E.; Luque-Márquez, R.; López-Cortés, L.F.; MartínezMarcos, F.J.; de la Torre-Lima, J.; Plata-Ciézar, A.; Hidalgo-Tenorio, C.; García-López, M.V.; et al. Ampicillin Plus Ceftriaxone Combined Therapy for Enterococcus faecalis Infective Endocarditis in OPAT. J. Clin. Med. 2022, 11, 7. https://doi.org/ $10.3390 /$ jcm 11010007

Academic Editors: Manuel Martínez-Sellés, Patricia Muñoz and Patrick De Boever

Received: 1 December 2021 Accepted: 16 December 2021 Published: 21 December 2021

Publisher's Note: MDPI stays neutral with regard to jurisdictional claims in published maps and institutional affiliations.

Copyright: (C) 2021 by the authors. Licensee MDPI, Basel, Switzerland. This article is an open access article distributed under the terms and conditions of the Creative Commons Attribution (CC BY) license (https:// creativecommons.org/licenses/by/ $4.0 /)$.
Unidad de Enfermedades Infecciosas, Hospital Juan Ramón Jiménez, 21005 Huelva, Spain; fcojmtz@telefonica.net

5 Unidad de Enfermedades Infecciosas, Servicio de Medicina Interna, Hospital Costa del Sol, 29603 Marbella, Spain; jtorrel@gmail.com

6 Servicio de Enfermedades Infecciosas, Hospital Regional Universitario de Malaga, 29010 Málaga, Spain; nonispc@hotmail.com

7 Servicio de Enfermedades Infecciosas, Hospital Universitario Virgen de las Nieves, 18014 Granada, Spain; chidalgo72@gmail.com

8 Servicio de Microbiología, Hospital Universitario Virgen de la Victoria, 29010 Málaga, Spain; mav.garcia@hotmail.com

9 Servicio de Enfermedades Infecciosas, Hospital Universitario San Cecilio, 18016 Granada, Spain; vinudav@yahoo.es

* Correspondence: mariav.gil.sspa@juntadeandalucia.es

\begin{abstract}
Ampicillin plus ceftriaxone (AC) is a well-recognized inpatient regimen for Enterococcus faecalis infective endocarditis (IE). In this regimen, ceftriaxone is usually administered $2 \mathrm{~g}$ every $2 \mathrm{~h}$ (AC12). The administration of AC in outpatient parenteral antibiotic treatment (OPAT) programs is challenging because multiple daily doses are required. AC regimens useful for OPAT programs include once-daily high-dose administration of ceftriaxone (AC24) or AC co-diluted and jointly administered in bolus every $4 \mathrm{~h}$ (ACjoined). In this retrospective analysis of prospectively collected cases, we aimed to assess the clinical effectivity and safety of three AC regimens for the treatment of E. faecalis IE. Fifty-nine patients were treated with AC combinations (AC12 $n=32$, AC24 $n=17$, and ACjoined $n=10)$. Six relapses occurred in the whole cohort: five (29.4\%) treated with AC24 regimen and one (10.0\%) with ACjoined. Patients were cured in $30(93.3 \%), 16(94.1 \%)$, and eight $(80.0 \%)$ cases in the AC12, AC24 and ACjoined groups, respectively. Unplanned readmission occurred in eight $(25.0 \%)$, six (35.3\%), and two $(20.0 \%)$ patients in the AC12, AC24 and ACjoined groups, respectively. The outcome of patients with E. faecalis IE treated with AC in OPAT programs relies on an optimization of the delivery of the combination. AC24 exhibit an unexpected rate of failures, however, ACjoined might be an effective alternative which clinical results should corroborate in further studies.
\end{abstract}

Keywords: Enterococcus faecalis; infective endocarditis; ampicillin; ceftriaxone; outpatient parenteral antibiotic treatment 


\section{Introduction}

Enterococcal endocarditis is a severe disease with incidence that has significantly increased in the last decades [1]. First-line antibiotic regimens recommended by international guidelines comprise the combination of a high-dose penicillin (ampicillin, amoxicillin or benzylpenicillin) plus a synergistic agent (ceftriaxone or gentamycin) for 4-6 weeks [2,3]. Outpatient parenteral antibiotic treatment (OPAT) is an advantageous alternative to long inpatient treatments, and the inclusion of patients with infective endocarditis (IE) has been globally endorsed [4,5]. The optimal treatment of E. faecalis IE in the outpatient setting has not yet been established, which is mostly attributed to the challenging adaptation of multi-dose fist line treatments in this scenario [6].

Ampicillin $2 \mathrm{~g}$ every $4 \mathrm{~h}$ plus ceftriaxone $2 \mathrm{~g}$ every $12 \mathrm{~h}$ combined therapy (AC12) is the preferred inpatient regimen, since it shows a lower rate of adverse effects than the regimens based on the combination of ampicillin plus gentamycin [7]. The major concerns regarding AC12 administration delivered via OPAT are ampicillin solution stability and the need for a twice-daily administration of ceftriaxone. Twice-daily visitation increases the resource consumption and prevents its global implantation in OPAT programs. Ampicillin administration through an electronic pump is a reliable option since a recent study clarified the existing doubts regarding stability in an OPAT scenario [8]. Different options should be considered with ceftriaxone administration: (i) maintaining the inpatient regimen, which implies twice-daily nurse visitation, (ii) grouping the daily dose in a single $4 \mathrm{~g}$ administration, (iii) dilute together with ampicillin for a joint administration of both antibiotics through an electronic pump (programmed to release $2 \mathrm{~g}$ of ampicillin and $666 \mathrm{mg}$ of ceftriaxone 4-hourly), since the stability of the combined solution has been recently proved [9]. The clinical experience with the regimen that included a single dailydose of ceftriaxone is only four cases reported with favourable results [10] and null with the joined administration.

The original ceftriaxone regimen ( $2 \mathrm{~g}$ every $12 \mathrm{~h}$ ) was design to theoretically maintain ceftriaxone plasma concentration over the stablished synergy threshold $(5 \mu \mathrm{g} / \mathrm{mL})$ between both antibiotics [11,12]. Recently, it has been demonstrated that both the original regimen and $4 \mathrm{~g}$ single daily-dose failed to maintain this concentration [13]. The pharmacokinetics of ceftriaxone administered $666 \mathrm{mg}$ every $4 \mathrm{~h}$ has not been studied, but it could be hypothesized that more frequent administration could help to achieve this goal.

We aimed to assess the clinical effectivity and safety of these three AC regimens for the treatment of $E$. faecalis infective endocarditis.

\section{Materials and Methods}

We performed a retrospective analysis of prospectively collected cases from a cohort attended at two tertiary hospitals between 2005 and 2021. Adult patients with definite or possible endocarditis, according to the modified Duke criteria [14], treated with an AC regimen for enterococcal endocarditis and recorded in pre-existing endocarditis and OPAT databases were selected. Length of therapy according with international guidelines was required [2,3]. Antimicrobial treatment and patient inclusion criteria in an OPAT program were settled on by a multidisciplinary team. The OPAT program included daily visitation by the nurse team for drug administration and clinical care, and weekly reviews by an infectious diseases physician.

Medical records were recorded prospectively to gather information including demographic data, episode of endocarditis, treatment management and clinical outcomes. All patients were initially treated with the inpatient AC regimen (ampicillin 2 g every $4 \mathrm{~h}$ plus ceftriaxone 2 g every $12 \mathrm{~h}$ ) until clinical and stabilization. AC continuation treatment was classified into three groups according to ceftriaxone administration: (i) patients who continued hospitalized with ceftriaxone $2 \mathrm{~g}$ every $12 \mathrm{~h}$ (AC12 group); (ii) patients included in the OPAT program treated with ceftriaxone 4 g every $24 \mathrm{~h}$ (AC24 group); (iii) patients included in the OPAT program treated with ceftriaxone diluted jointly with ampicillin and administered in pulses every $4 \mathrm{~h}(2 \mathrm{~g}$ de ampicillin $+666 \mathrm{mg}$ of ceftriaxone every $4 \mathrm{~h})$ 
(ACjoined group). Patients included between 2005 and the start date of our OPAT program (2012) were treated with the AC12 regimen. Ampicillin dose regimen was 2 g every $4 \mathrm{~h}$, except for renal impairment adjustments.

Infective endocarditis was classified depending on the location (right vs left side) and the valve or cardiac device involved. The Charlson comorbidity index was used to grade overall morbidity at the time of diagnosis [15]. Minimum and maximum followup were established at 6 and 12 months, respectively, after completion of the antibiotic treatment, with periodic clinical reviews and follow-up blood cultures to ensure definitive microbiological cure. Outcomes assessed during the follow-up period were: (i) relapse, defined as positive blood cultures caused by the same microorganism as the initial episode; (ii) overall mortality, defined as death from any cause; (iii) endocarditis-related mortality, defined as death derived from the infection or its sequalae; and (iv) adverse events related with AC treatment. For those relapses observed after six months of treatment stop-date, pulsed field gel electrophoresis (PFGE) was used to distinguish the strains [16]. STROBE guidelines for reporting observational studies were followed [17]. The study was approved by the Ethics Committee for Clinical Research of Seville (2396-N-21).

The statistical analysis was performed using R-studio and SPSS version 28.0 (SPSS Inc., Chicago, IL, USA). Categorical variables were summarized as percentages. Continuous variables were summarized as median and interquartile range (IQR). Quantitative variables were compared using a Kruskal-Wallis test and categorical variables were compared using the Chi-Square test. A two-sided $p<0.05$ was considered statistically significant.

\section{Results}

Fifty-nine patients with E. faecalis IE were treated with AC combinations. The treatment was AC12, AC24 and ACjoined in 32 (54.2\%), 17 (28.8\%) and 10 (17.0\%) patients, respectively (Table 1 ). Comorbidities did not differ significantly between the three groups, with the exception of colorectal disease, which was more frequent in the AC24 group (52.9\%) respect to the AC12 and ACjoined groups (12.5\% and 30\%, respectively) $(p=0.01)$. A trend towards $(p=0.07)$ a worse Charlson score has been observed in the OPAT regimens, although it was not statistically significant. The median duration of AC treatment was 42 days and was similar between the three groups. Regarding the OPAT regimens (AC24 and ACjoined), the median duration of inpatient antibiotic treatment prior to OPAT was $26.6 \pm 9.3$ and $16.2 \pm 8.3$ days in the AC24 and ACjoined groups, respectively $(p=0.007)$.

Table 1. Baseline characteristics.

\begin{tabular}{|c|c|c|c|c|c|}
\hline Baseline Characteristics & Overall $(n=59)$ & $\operatorname{AC12}(n=32)$ & $\begin{array}{c}\text { Treatment } \\
\text { AC24 }(n=17)\end{array}$ & ACjoined $(n=10)$ & $p$ \\
\hline Age (median (IQR)) & $68(59-77)$ & $64(57-73)$ & $73(60-80)$ & $73(59-77)$ & 0.127 \\
\hline Male gender & $37(62.7)$ & $18(56.3)$ & $13(76.5)$ & $6(60.0)$ & 0.372 \\
\hline Charlson score (median (IQR)) & $4(3-5)$ & $3(2-5)$ & $5(3.5-5.5)$ & $5(3.75-5.5)$ & 0.07 \\
\hline \multicolumn{6}{|l|}{ Comorbidities } \\
\hline Hypertension & $32(54.2)$ & $16(50.0)$ & $9(52.9)$ & $7(70.0)$ & 0.537 \\
\hline Diabetes mellitus & $17(28.8)$ & $11(34.4)$ & $3(17.6)$ & $3(30.0)$ & 0.467 \\
\hline Hyperlipidaemia & $20(33.9)$ & $9(28.1)$ & $7(41.2)$ & $4(40.0)$ & 0.593 \\
\hline Chronic renal failure & $13(22.0)$ & $9(28.1)$ & $3(17.6)$ & $1(10.0)$ & 0.422 \\
\hline Colorectal disease & $16(27.1)$ & $4(12.5)$ & $9(52.9)$ & $3(30.0)$ & 0.010 \\
\hline Chronic obstructive pulmonary disease & $8(13.6)$ & $6(18.8)$ & $2(11.8)$ & $0(0.0)$ & 0.309 \\
\hline Cancer & $9(15.3)$ & $5(15.6)$ & $4(23.5)$ & $0(0.0)$ & 0.259 \\
\hline Peripheral vascular disease & $9(15.3)$ & $2(6.3)$ & $4(23.5)$ & $3(30.0)$ & 0.101 \\
\hline Liver disease & $6(10.2)$ & $5(15.6)$ & $1(5.9)$ & $0(0.0)$ & 0.284 \\
\hline Previous cerebrovascular accident & $5(8.5)$ & $2(6.3)$ & $2(11.8)$ & $1(10.0)$ & 0.790 \\
\hline Previous IE episode & $3(5.1)$ & $0(0.0)$ & $2(11.8)$ & $1(10.0)$ & 0.094 \\
\hline Prosthetic valve/Pacemaker carrier (involved or not) * & $22(37.3)$ & $9(28.1)$ & $7(41.2)$ & $6(60.0)$ & 0.177 \\
\hline \multicolumn{6}{|l|}{ Prosthetic valve location (involved or not) } \\
\hline $\begin{array}{l}\text { Prosthetic aortic valve } \\
\text { Pos }\end{array}$ & $20(33.9)$ & $7(21.9)$ & $7(41.2)$ & $6(60.0)$ & 0.148 \\
\hline Prosthetic mitral valve & $4(6.8)$ & $2(6.3)$ & $1(5.9)$ & $1(10.0)$ & 0.925 \\
\hline Prosthetic tricuspid valve & $1(1.7)$ & $1(3.1)$ & $0(0.0)$ & $0(0.0)$ & 0.601 \\
\hline \multicolumn{6}{|l|}{ Type of prosthesis (involved or not) * } \\
\hline Valvular prosthesis & $17(28.8)$ & $7(21.9)$ & $5(29.4)$ & $5(50.00)$ & \\
\hline Pacemaker & $4(6.8)$ & $2(6.3)$ & $2(11.8)$ & $0(0.0)$ & 0.555 \\
\hline TAVI & $3(5.1)$ & $0(0.0)$ & $2(11.8)$ & $1(10.00)$ & \\
\hline
\end{tabular}

Bold indicates statistical significance, IQR = Interquartile range, IE = Infective endocarditis, TAVI = Transaortic valve implantation, * Some patients carried more than one prosthetic valve or a prosthetic valve and a pacemaker. 
Forty-three $(72.9 \%)$ were classified as definite IE and $16(27.1 \%)$ as possible IE in accordance with the modified Duke criteria. Fourteen patients (23.7\%) presented more than one structure involved in the infection (Table 2). Prosthetic valve IE was diagnosed in seven $(21.9 \%)$, four $(23.5 \%)$ and six $(60.0 \%)$ patients in AC12, AC24 and ACjoined $(p=0.025)$, respectively. Twenty-five percent $(n=8)$ of the surgery indicated was never performed, two in the AC12 group ( $10 \%$ of indicated surgery), four in the AC24 group ( $40 \%$ of indicated surgery) and two in the ACjoined group (100\% of indicated surgery).

Table 2. Infection-related characteristics and clinical outcomes.

\begin{tabular}{|c|c|c|c|c|c|}
\hline Endocarditis Characteristics & Overall $(n=59)$ & $\operatorname{AC12}(n=32)$ & $\begin{array}{c}\text { Treatment } \\
\text { AC24 }(n=17)\end{array}$ & ACjoined $(n=10)$ & $p$ \\
\hline \multicolumn{6}{|l|}{ Type of endocarditis } \\
\hline Left-side IE & $53(89.8)$ & $29(90.6)$ & $16(94.1)$ & $8(80.0)$ & \multirow{3}{*}{0.515} \\
\hline Right-side IE & $2(3.4)$ & $1(3.1)$ & $0(0.0)$ & $1(10.0)$ & \\
\hline Left and right-side IE & $1(1.7)$ & $1(3.1)$ & $0(0.0)$ & $0(0.0)$ & \\
\hline Other or unknown & $3(5.1)$ & $1(3.1)$ & $1(5.9)$ & $1(10.0)$ & \\
\hline Native valve IE & $39(66.1)$ & $25(78.1)$ & $11(64.7)$ & $3(30.0)$ & 0.019 \\
\hline Early prosthetic valve IE (<1 year) & $7(11.9)$ & $2(6.3)$ & $1(5.9)$ & $4(40.0)$ & 0.010 \\
\hline Late prosthetic valve IE ( $>1$ year) & $10(16.9)$ & $5(15.6)$ & $3(17.6)$ & $2(20.0)$ & 0.946 \\
\hline Cardiac device-related IE & $3(5.1)$ & $0(0.0)$ & $2(11.8)$ & $1(10.0)$ & 0.151 \\
\hline \multicolumn{6}{|l|}{ Valve involvement } \\
\hline Aortic valve & $28(47.5)$ & $16(50.0)$ & $8(47.1)$ & $4(40.0)$ & 0.858 \\
\hline Mitral valve & $14(23.7)$ & $8(25.0)$ & $4(23.5)$ & $2(20.0)$ & 0.948 \\
\hline Mitral and aortic valves & $11(18.6)$ & $5(15.6)$ & $4(23.5)$ & $2(20.0)$ & 0.790 \\
\hline Mitral and tricuspid valves & $1(1.7)$ & $1(3.1)$ & $0(0.0)$ & $0(0.0)$ & 0.651 \\
\hline IVC and tricuspid valve & $2(3.4)$ & $1(3.1)$ & $0(0.0)$ & $1(10.0)$ & 0.380 \\
\hline Other or unknown & $3(5.1)$ & $1(3.1)$ & $1(5.9)$ & $1(10.0)$ & 0.678 \\
\hline \multicolumn{6}{|l|}{ Cardiac Surgery } \\
\hline Cardiac surgery indicated * & $32(54.2)$ & $20(62.5)$ & $10(58.8)$ & $2(20.0)$ & 0.049 \\
\hline Cardiac surgery performed ( $\%$ of indicated) & $24(75.0)$ & $18(90.0)$ & $6(60.0)$ & $0(0.0)$ & 0.008 \\
\hline \multicolumn{6}{|l|}{ Clinical outcomes } \\
\hline Relapses & $6(10.2)$ & $0(0.0)$ & $5(29.4)$ & $1(10.0)$ & 0.005 \\
\hline Side effects related to $\mathrm{AC}$ & $7(11.9)$ & $6(18.8)$ & $0(0.0)$ & $1(10.0)$ & 0.152 \\
\hline Unplanned readmission & $17(28.8)$ & $9(28.1)$ & $6(35.3)$ & $2(20.0)$ & 0.693 \\
\hline Readmission unrelated to IE & $8(13.6)$ & $5(15.6)$ & $2(11.8)$ & $2(20.0)$ & \multirow{2}{*}{0.260} \\
\hline Readmission related to IE & $9(15.3)$ & $4(12.5)$ & $5(29.4)$ & $0(0.0)$ & \\
\hline \multicolumn{6}{|l|}{ Final outcome } \\
\hline Cured & $54(91.5)$ & $30(93.8)$ & $16(94.1)$ & $8(80.0)$ & \multirow{3}{*}{0.177} \\
\hline Death unrelated to IE & $2(3.4)$ & $1(3.1)$ & $1(5.9)$ & $0(0.0)$ & \\
\hline Death related to IE & $3(5.1)$ & $1(3.1)$ & $0(0.0)$ & $2(20.0)$ & \\
\hline
\end{tabular}

Bold indicates statistical significance, $\mathrm{IQR}=$ Interquartile range, $\mathrm{IE}=$ Infective endocarditis, $\mathrm{AC}=\mathrm{Ampicillin}$ plus ceftriaxone treatment, IVC $=$ Interventricular communication, ${ }^{*}$ Surgical indications were evaluated according to the American Association for Thoracic Surgery (AATS) guidelines [18].

Six relapses occurred in the complete whole: five (29.4\%) patients had been treated with AC24 regimen and one (10.0\%) patient with ACjoined. Relapsed episodes are detailed in Table 3. Among the patients receiving a complete in-patient treatment (AC12), 30 (93.3\%) of them were cured and two (6.3\%) died. Unplanned readmission after hospital discharge occurred in eight $(25.0 \%)$ of them during the follow-up period (cardiac insufficiency $n=3$; deep vein thrombosis $n=1$; cerebral hemorrhage $n=1$, decreased level of consciousness $n=1$; cardiorespiratory arrest $n=1$; and late hypersensitivity to antibiotics and tachycardia $n=1)$. Patients included in OPAT ( $n=27,45.8 \%)$ were treated with AC24 or ACjoined as continuation regimens. Out of the seventeen patients treated with AC24, $16(94.1 \%)$ were cured and one $(5.9 \%)$ died. Six (35.3\%) of them required unplanned hospitalization, in four $(23.5 \%)$ cases due to relapses, in one due to cardiac insufficiency, and one operated patient with a new IE episode caused by another microorganism. The mean length of inpatient treatment in AC24 relapsed episodes was $16.8 \pm 4.0$ days, whilst the not-relapsed group was $30.6 \pm 7.6$ days $(p=0.003)$. Ten patients received ACjoined as continuation regimen. Among them, eight $(80.0 \%)$ were cured and two $(20.0 \%)$ of them died. In both cases surgery had been indicated but not performed. In this cohort unplanned readmission occurred in two $(20.0 \%)$ patients (cerebral toxoplasmosis $n=1$; and pseudomembranous colitis $n=1$ ). One patient in the ACjoined group completed the last 7 days of treatment with oral therapy due to a vascular access complication. Seven patients experienced side effects related to 
AC treatment, six (85.0\%) belonging to the AC12 group and one $(15.0 \%)$ to the ACjoined group $(p=0.152)$ (Table 2$)$.

Table 3. Description of relapsed episodes.

\begin{tabular}{|c|c|c|c|c|c|c|}
\hline Age & $\mathrm{CS}^{\#}$ & Type IE & AC Group & Surgery $(\mathbf{i} / \mathrm{p}) *$ & Commentaries & $\begin{array}{c}\text { Outcome } \\
\text { (Follow-Up) }\end{array}$ \\
\hline 87 & 6 & $\begin{array}{l}\text { Early prosthetic aortic valve IE in a } \\
\text { patient with a pacemaker }\end{array}$ & $\mathrm{AC} 24$ & No/No & $\begin{array}{l}\text { Pacemaker replacement (pacemaker } \\
\text { wire cultures negative) and } \\
\text { treatment with daptomycin } \\
\text { followed by dalbavancin ( } 9 \text { weeks) }\end{array}$ & $\begin{array}{l}\text { Cure } \\
\text { (1 year) }\end{array}$ \\
\hline 60 & 1 & $\begin{array}{l}\text { Native mitral valve IE in a patient with a } \\
\text { prosthetic aortic valve }\end{array}$ & $\mathrm{AC} 24$ & No/No & $\begin{array}{l}\text { Treatment with teicoplanin } \\
\text { (8 weeks) }\end{array}$ & $\begin{array}{l}\text { Cure } \\
\text { (1 year) }\end{array}$ \\
\hline 68 & 3 & $\begin{array}{l}\text { Early prosthetic mitral and aortic valve } \\
\text { IE in a patient with a pacemaker }\end{array}$ & AC24 & No/No & $\begin{array}{l}\text { Treatment with ampicillin (6 weeks) } \\
\text { plus gentamicin ( } 2 \text { weeks). }\end{array}$ & $\begin{array}{l}\text { Cure } \\
\text { (1 year) }\end{array}$ \\
\hline 73 & 4 & Native mitral valve IE & AC24 & No/No & $\begin{array}{l}\text { Treatment with ampicillin (6 weeks) } \\
\text { plus gentamicin ( } 2 \text { weeks). Second } \\
\text { relapse and treatment with } \\
\text { ampicillin plus teicoplanin followed } \\
\text { by amoxicillin plus moxifloxacin } \\
\text { (10 weeks) }\end{array}$ & $\begin{array}{l}\text { Cure } \\
\text { (1 year) }\end{array}$ \\
\hline 81 & 4 & $\begin{array}{l}\text { Native mitral and aortic valve IE with } \\
\text { pseudoaneurysm of the radial and } \\
\text { femoral arteries }\end{array}$ & AC24 & No/No & $\begin{array}{l}\text { Treatment with ampicillin plus } \\
\text { ceftriaxone ( } 6 \text { weeks) and } \\
\text { cardiac surgery }\end{array}$ & $\begin{array}{l}\text { Cure } \\
\text { (1 year) }\end{array}$ \\
\hline 88 & 5 & $\begin{array}{l}\text { Native mitral and prosthetic aortic valve } \\
\text { complicated IE with pseudoaneurysm of } \\
\text { the mitral-aortic intervalvular fibrosa }\end{array}$ & $\begin{array}{c}\mathrm{AC} \\
\text { joined }\end{array}$ & Yes/No & Relapsed and death & $\begin{array}{l}\text { Death } \\
\text { (2 months) }\end{array}$ \\
\hline
\end{tabular}

${ }^{\#}$ CS: Charlson score, ${ }^{*}(\mathrm{i} / \mathrm{p})$ : Surgery indicated/Surgery performed. Surgical indications were evaluated according to the American Association for Thoracic Surgery (AATS) guidelines [18].

\section{Discussion}

This is the first study showing how to adapt AC combination to the outpatient setting and comparing clinical results of two AC dose regimens for $E$. faecalis infective endocarditis in OPAT programs and the conventional inpatient AC regimen. This double $\beta$-lactam combination has been endorsed by preclinical data proving its synergistic activity [11,12] and clinical good results in extensive cohorts [6], being nowadays recognized as an alternative to ampicillin plus gentamycin regimens by international guidelines for $E$. faecalis infective endocarditis as first line therapy [2,3].

$\mathrm{AC}$ administration at home requires some adjustment given the difficulty of delivering a twice-daily ceftriaxone regimen. We proposed two new AC schemes: AC24 and ACjoined. AC24 comprises the administration of a single-daily dose of $4 \mathrm{~g}$ of ceftriaxone. This regimen allows once-daily nurse visitation, but it might implicate drug insufficient concentrations to maintain the synergistic activity $8 \mathrm{~h}$ after the dose [13]. In this cohort, we found a greater number of relapses $(29.4 \%)$ in patients treated with the AC24 continuation regimen than the original AC12 (0.0\%). This high number of relapses could be influenced by the large number of patients with prosthetic valve infection and device-related infections, the poor initial condition and the lack of surgical management despite being indicated as risk factors for treatment failure [19]. Additionally, time until discharge was shorter than 21 days in all relapses, which raises the question that $\mathrm{AC} 24$ might be insufficient due to low ceftriaxone concentrations after $18 \mathrm{~h}$ with this dosing regimen [13], and suggesting that the clinical success might be attributed to a longer inpatient treatment under the AC12 regimen for at least three weeks. Despite the possible explanations detailed, caution is required when treating enterococcal endocarditis with the AC24 scheme in OPAT programs.

Continuous infusion of benzylpenicillin plus ceftriaxone (BC) has been recently explored as a double $\beta$-lactam combination in the outpatient setting $[20,21]$. This combination raises some concerns that must be addressed. Firstly, it has been assumed that the synergistic activity exhibited by $\mathrm{AC}[14,15]$ is preserved in $\mathrm{BC}$ combination [20]. However, recent studies have shown poor correlation between $\mathrm{AC}$ and $\mathrm{BC}$ synergistic activity and lower rates of this interaction with $\mathrm{BC}$ in E. faecalis clinical strains [21,22]. Secondly, ceftriaxone dose regimen adjustment for OPAT entails the same difficulty shown in the AC regimen. 
In these studies, ceftriaxone dosing was highly variable and included regimens unable to provide synergy [13], such as, for example, $2 \mathrm{~g}$ daily dose [20]. Finally, clinical outcomes from $E$. faecalis IE treated with BC were controversial. One study exhibited a low relapse rate $(5 \%)$, whereas $35 \%$ of the patients continued with long-term suppressive antibiotic treatment after BC completion [20]. Another study showed high rates of unplanned readmissions (30\%), although rates of relapsed bacteremia (5\%) were low [21]. Overall, prior to recommending $\mathrm{BC}$ therapy further investigation is still required, not only for efficacy and dosing design, but also for the molecular basis of the combination.

As an alternative, we present an AC scheme suitable for the outpatient setting with promising results. ACjoined consist in the co-dilution of the daily dose of both antibiotics in the same solution and the administration together through an electronic pump in bolus every $4 \mathrm{~h}$. Initially, this option was avoided due to the absent of stability data. Nevertheless, once drug stability had been proved in similar conditions than the OPAT program [9], ACjoined was used as continuation treatment for patients with enterococcal endocarditis. In our population treated with ACjoined, only one patient relapsed (10\%) in spite of none of the indicated surgery being performed and the elevated number of prosthetic endocarditis included $(60.0 \%)$. However, despite these promising results, further investigation is required to consolidate the ACjoined scheme as the best option for the treatment of $E$. faecalis IE in OPAT programs.

Other therapeutic alternatives for E. faecalis IE outpatient continuation regimen have been discussed [6]. Dalbavancin and teicoplanin are antibiotics with long half-life which are easily included in OPAT programs. The experience with these antibiotics in this scenario is limited but promising, especially for teicoplanin $[23,24]$. Another option, recently endorsed by the results of a large clinical trial, for the continuation regimen of E. faecalis infective endocarditis is oral treatment, although, E. faecalis episodes included were scarce [25].

The interpretation of our study results is bounded by its retrospective design and the low number of patients included. Furthermore, follow-up period varied between 6 and 12 months, which could be insufficient for later relapses. Despite of these limitations, our study paves the way for further investigation regarding the administration of fist line regimens for enterococcal endocarditis in the outpatient setting.

\section{Conclusions}

The outcome of patients with E. faecalis IE treated with AC in OPAT programs relies on an optimization of the delivery of the combination. AC24 exhibit an unexpected rate of failures, but ACjoined might be an effective alternative which clinical results should corroborate in further studies.

Author Contributions: L.H.-H. wrote the manuscript; L.H.-H., J.M.L.-C., A.D.A., L.E.L.-C., M.V.G.-N and R.L.-M. designed the research; L.H.-H. and J.M.L.-C. conducted the research and analysed the data; all authors reviewed and contributed to the final manuscript. All authors have read and agreed to the published version of the manuscript.

Funding: The authors received no financial support for the research, authorship, and/or publication of this article. GVA was supported by the Instituto de Salud Carlos III, cofinanced by the European Development Regional Fund ("A way to achieve Europe"), Subprograma Miguel Servet (grant CP19/00159). HHL was supported by the Instituto de Salud Carlos III, Subprograma Rio Hortega (grant CM19/00152).

Institutional Review Board Statement: The study was approved by the Ethics Committee for Clinical Research of Seville (2396-N-21).

Informed Consent Statement: Patient consent was waived due to the retrospective design of the study.

Acknowledgments: We would like to pay our gratitude and our respects to our colleague Juan Gálvez Acebal ("In memoriam") for his contribution and dedication to the E. faecalis infective endocarditis study team and the "Grupo para el Estudio de las Infecciones Cardiovasculares de la Sociedad Andaluza de Enfermedades Infecciosas". 
Conflicts of Interest: L.F.L.-C. has received unrestricted research funding from Abbvie, Bristol-Myers Squibb, Gilead Sciences, Janssen-Cilag, Merck Sharp \& Dohme, and ViiV Healthcare, and consultancy fees and lecture fees from Abbvie, Bristol-Myers Squibb, Gilead Sciences, Janssen-Cilag, and ViiV Healthcare, outside the submitted work. L.E.L.-C. has served as scientific advisor for Angelini, speaker for Angelini, ViiV, Gilead and Correvio, and has served as trainer for ViiV. A.D.A. has served as scientific advisor for Angellini, Novartis, Roche and Cook, speaker for MSD, Pfizer, Angellini, Novartis, Roche and ViiV, and has served as trainer for MSD. The remaining authors have none to declare.

\section{References}

1. Olmos, C.; Vilacosta, I.; Fernández-Pérez, C.; Bernal, J.L.; Ferrera, C.; García-Arribas, D.; Pérez-García, C.N.; San Román, J.A.; Maroto, L.; Macaya, C.; et al. The Evolving Nature of Infective Endocarditis in Spain: A Population-Based Study (2003 to 2014). J. Am. Coll. Cardiol. 2017, 70, 2795-2804. [CrossRef]

2. Habib, G.; Lancellotti, P.; Antunes, M.J.; Bongiorni, M.G.; Casalta, G.-P.; Del Zotti, F.; Dulgheru, R.; El Khoury, G.; Erba, P.A.; Iung, B.; et al. 2015 ESC Guidelines for the management of infective endocarditis: The Task Force for the Management of Infective Endocarditis of the European Society of Cardiology (ESC). Endorsed by: European Association for Cardio-Thoracic Surgery (EACTS), the European. Eur. Heart J. 2015, 36, 3075-3128. [CrossRef]

3. Baddour, L.M.; Wilson, W.R.; Bayer, A.S.; Fowler, V.G., Jr.; Tleyjeh, I.M.; Rybak, M.J.; Barsic, B.; Lockhart, P.B.; Gewitz, M.H.; Levison, M.E.; et al. Infective endocarditis in adults: Diagnosis, antimicrobial therapy, and management of complications: A scientific statement for healthcare professionals from the American Heart Association. Circulation 2015, 132, 1435-1486. [CrossRef]

4. Norris, A.H.; Shrestha, N.K.; Allison, G.M.; Keller, S.C.; Bhavan, K.P.; Zurlo, J.J.; Hersh, A.L.; Gorski, L.A.; Bosso, J.A.; Rathore, M.H.; et al. 2018 IDSA Clinical Practice Guideline for the Management of Outpatient Parenteral Antimicrobial Therapy. Clin. Infect. Dis. 2018, 68, e1-e35. [CrossRef]

5. Pericàs, J.M.; Llopis, J.; González-ramallo, V.; Goenaga, M.Á.; Muñoz, P.; García-Leoni, M.E.; Fariñas, M.C.; Pajarón, M.; Ambrosioni, J.; Luque, R.; et al. Outpatient Parenteral Antibiotic Treatment (OPAT) for Infective Endocarditis: A Prospective Cohort Study from the GAMES Cohort. Clin. Infect. Dis. 2019, 69, 1690-1700. [CrossRef]

6. Herrera-Hidalgo, L.; de Alarcón, A.; López-Cortes, L.E.; Luque-Márquez, R.; López-Cortes, L.F.; Gutiérrez-Valencia, A.; GilNavarro, M.V. Enterococcus faecalis endocarditis and outpatient treatment: A systematic review of current alternatives. Antibiotics 2020, 9, 657. [CrossRef]

7. Fernández-Hidalgo, N.; Almirante, B.; Gavaldà, J.; Gurgui, M.; Peña, C.; De Alarcón, A.; Ruiz, J.; Vilacosta, I.; Montejo, M.; Vallejo, N.; et al. Ampicillin plus ceftriaxone is as effective as ampicillin plus gentamicin for treating enterococcus faecalis infective endocarditis. Clin. Infect. Dis. 2013, 56, 1261-1268. [CrossRef]

8. Maher, M.; Jensen, K.J.; Lee, D.; Nix, D.E. Stability of Ampicillin in Normal Saline and Buffered Normal Saline. Int. J. Pharm. Compd. 2016, 20, 338-342.

9. Herrera-Hidalgo, L.; López-Cortes, L.E.; Luque-Márquez, R.; Gálvez-Acebal, J.; de Alarcón, A.; López-Cortes, L.F.; GutiérrezValencia, A.; Gil-Navarro, M.V. Ampicillin and ceftriaxone solution stability at different temperatures useful for outpatient parenteral antimicrobial therapy (OPAT). Antimicrob. Agents Chemother. 2020, 64, e00309-20. [CrossRef]

10. Gil-Navarro, M.V.; Lopez-Cortes, L.E.; Luque-Marquez, R.; Galvez-Acebal, J.; de Alarcon-Gonzalez, A. Outpatient parenteral antimicrobial therapy in Enterococcus faecalis infective endocarditis. J. Clin. Pharm. Ther. 2018, 43, 220-223. [CrossRef] [PubMed]

11. Gavaldà, J.; Torres, C.; Tenorio, C.; López, P.; Zaragoza, M.; Capdevila, J.A.; Almirante, B.; Ruiz, F.; Borrell, N.; Gomis, X.; et al. Efficacy of ampicillin combined with ceftriaxone and gentamicin in the treatment of experimental endocarditis due to Enterococcus faecalis with no high-level resistance to aminoglycosides. J. Antimicrob. Chemother. 2003, 52, 514-517. [CrossRef]

12. Gavaldà, J.; Torres, C.; Tenorio, C.; López, P.; Zaragoza, M.; Capdevila, J.A.; Almirante, B.; Ruiz, F.; Borrell, N.; Gomis, X.; et al Efficacy of ampicillin plus ceftriaxone in treatment of experimental endocarditis due to Enterococcus faecalis strains highly resistant to aminoglycosides. Antimicrob. Agents Chemother. 1999, 43, 639-646. [CrossRef]

13. Herrera-Hidalgo, L.; de Alarcón, A.; López-Cortes, L.E.; Luque-Márquez, R.; López-Cortes, L.F.; Gutiérrez-Valencia, A.; GilNavarro, M.V. Is once-daily high-dose ceftriaxone plus ampicillin an alternative for enterococcus faecalis infective endocarditis in outpatient parenteral antibiotic therapy programs? Antimicrob. Agents Chemother. 2021, 65, e02099-20. [CrossRef] [PubMed]

14. Li, J.S.; Sexton, D.J.; Mick, N.; Nettles, R.; Fowler, J.V.G.; Ryaln, T.; Bashore, T.; Corey, G.R. Proposed Modifications to the Duke Criteria for the Diagnosis of Infective Endocarditis. Clin. Infect. Dis. 2000, 30, 633-638. [CrossRef]

15. Charlson, M.E.; Pompei, P.; Ales, K.L.; Mackenzie, C.R. A new method of classifying prognostic comorbidity in longitudinal studies: Development and validation. J. Chronic Dis. 1987, 40, 373-383. [CrossRef]

16. López-Cortés, L.E.; Fernández-Cuenca, F.; Luque-Márquez, R.; de Alarcón, A. Enterococcal Endocarditis: Relapses or Reinfections. Clin. Infect. Dis. 2021, 72, 360-361. [CrossRef] [PubMed]

17. Von Elm, E.; Altman, D.G.; Egger, M.; Pocock, S.J.; Gøtzsche, P.C.; Vandenbroucke, J.P. The Strengthening the Reporting of Observational Studies in Epidemiology (STROBE) Statement: Guidelines for Reporting Observational Studies. 2007. Available online: www.plosmedicine.org (accessed on 1 October 2021).

18. Pettersson, G.B.; Hussain, S.T. Current AATS guidelines on surgical treatment of infective endocarditis. Ann. Cardiothorac. Surg. 2019, 8, 630-644. [CrossRef] 
19. Pericàs, J.M.; Llopis, J.; Muñoz, P.; Gálvez-Acebal, J.; Kestler, M.; Valerio, M.; Hernández-Meneses, M.; Goenaga, M.Á.; CoboBelaustegui, M.; Montejo, M.; et al. A Contemp. Pict. Enterococcal Endocarditis. J. Am. Coll. Cardiol. 2020, 75, 482-494. [CrossRef]

20. Briggs, S.; Broom, M.; Duffy, E.; Everts, R.; Everts, G.; Lowe, B.; McBride, S.; Bhally, H. Outpatient continuous-infusion benzylpenicillin combined with either gentamicin or ceftriaxone for enterococcal endocarditis. J. Antimicrob. Chemother. 2021, 76, 2168-2171. [CrossRef]

21. Ingram, P.R.; Ng, J.; Mathieson, C.; Mowlaboccus, S.; Coombs, G.; Raby, E.; Dyer, J. A clinical and in vitro assessment of outpatient parenteral benzylpenicillin and ceftriaxone combination therapy for enterococcal endovascular infections. JAC-Antimicrob. Resist. 2021, 3, dlab128. [CrossRef]

22. Thieme, L.; Briggs, S.; Duffy, E.; Makarewicz, O.; Pletz, M.W. In vitro synergism of penicillin and ceftriaxone against enterococcus faecalis. Microorganisms 2021, 9, 2150. [CrossRef] [PubMed]

23. De Nadaï, T.; François, M.; Sommet, A.A.; Dubois, D.; Metsu, D.; Grare, M.; Marchou, B.; Delobel, P.; Martin-Blondel, G. Efficacy of teicoplanin monotherapy following initial standard therapy in Enterococcus faecalis infective endocarditis: A retrospective cohort study. Infection 2019, 47, 463-469. [CrossRef]

24. Escolà-Vergé, L.; Fernández-Hidalgo, N.; Rodríguez-Pardo, D.; Pigrau, C.; González-López, J.J.; Bartolomé, R.; Almirante, B. Teicoplanin for treating enterococcal infective endocarditis: A retrospective observational study from a referral centre in Spain. Int. J. Antimicrob. Agents 2019, 53, 165-170. [CrossRef] [PubMed]

25. Iversen, K.; Ihlemann, N.; Gill, S.U.; Madsen, T.; Elming, H.; Jensen, K.T.; Bruun, N.E.; Høfsten, D.E.; Fursted, K.; Christensen, J.J.; et al. Partial oral versus intravenous antibiotic treatment of endocarditis. N. Engl. J. Med. 2019, 380, 415-424. [CrossRef] [PubMed] 